\title{
USO DE OBRAS HUÉRFANAS: ESTUDIO DE DIVERSAS REGULACIONES EN EL DERECHO COMPARADO COMO REFERENCIA PARA MODERNIZAR LA REGULACIÓN CHILENA SOBRE PROPIEDAD INTELECTUAL ${ }^{1}$
}

\author{
USE OF ORPHAN WORKS: STUDYING DIFFERENT REGULATIONS IN \\ COMPARATIVE LAW AS A REFERENCE FOR UPGRADING CHILEAN \\ INTELLECTUAL PROPERTY LAW
}

\section{Elisa Walker ECheniQue}

\begin{abstract}
RESUMEN: Históricamente, la propiedad intelectual ha tenido que adaptarse a nuevos desafíos, principalmente impuestos por el avance tecnológico. Uno de los desafíos es la incertidumbre que produce la existencia de obras huérfanas, particularmente debido a los obstáculos que estas generan en la digitalización masiva. El objetivo de este artículo es explicar qué son las obras huérfanas, cuáles son los problemas generados en el ejercicio de derechos y revisar regulaciones que han propuesto soluciones para asegurar acceso a las mismas. El estudio de este tema es importante ya que las obras huérfanas no han sido reguladas en Chile. De esta forma, es necesario analizar posibles soluciones que puedan ser eventualmente incorporadas a la legislación nacional.
\end{abstract}

Palabras clave: Obra huérfana, propiedad intelectual, régimen de excepciones, licencias sobre obras huérfanas, licencia colectiva ampliada.

ABSTRACT: Historically, intellectual property has had to adapt to new challenges that have mainly been imposed by the advancement of technology. A recent challenge is the uncertainty produced by the existence of orphan works, particularly due to the obstacles that they generate in mass digitization. This article aims to explain orphan works, the problems generated by rights management, and review regulations that have offered solutions to assure access to thems. This study is important because orphan works have not been regulated in Chile. Therefore, it is necessary to analyze possible solutions that may eventually be incorporated into national legislation.

Key words: Orphan work, intellectual property law, exceptions, orphan works licensing, extended collective licensing.

\section{INTRODUCCIÓN}

El año 2002 Google empezó a gestionar un proyecto que tenía por objetivo digitalizar millones de libros para ponerlos a disposición de los usuarios a través de Internet. Este proyecto es conocido como Google Books. Junto con poner a disposición una versión

\footnotetext{
${ }^{1}$ Elisa Walker, Abogada Universidad de Chile, Magíster en Innovación, Tecnología y Derecho, Universidad de Edimburgo, Docente Universidad Adolfo Ibáñez. Correo electrónico: elisa.walker@uai.cl / elawalker@gmail.com Quiero agradecer la colaboración de Santiago Schuster, Jorge Mahú y los árbitros que colaboraron en la evaluación de este artículo. Todos ellos permitieron que el texto que está a si disposición fuese mejor que el original.
} 
digitalizada de un libro, Google Books también ofrecía un sistema de búsqueda de contenido que permitía a los usuarios identificar diversos libros que puedan estar relacionados con un tema de interés y de esa forma agilizar un trabajo de investigación ${ }^{2}$.

El desafío de digitalizar colecciones completas de libros generó un intenso debate sobre el impacto que este proyecto producía en relación a la protección de la propiedad intelectual. La labor realizada por Google fue cuestionada debido a que la digitalización de un libro constituye una reproducción del mismo, por lo que dicha actividad debería estar amparada por una autorización previa del titular de derecho para que esta fuese legítima ${ }^{3}$. Asimismo, el proyecto de Google fue objeto de reparos por haber digitalizado obras huérfanas. Las obras huérfanas son generalmente conocidas como todas aquellas que están protegidas por la propiedad intelectual pero cuyo titular de derechos no puede ser localizado o identificado, lo que imposibilita la obtención de una autorización previa para usar dichas obras. La falta de identificación o localización del titular de derechos genera una gran incertidumbre ya que estos factores no son razón suficiente para prescindir de la autorización del titular de derechos en el caso que se quiera usar una obra huérfana, salvo que una regulación legal así lo disponga. De tal forma, se produce una paradoja. Por un lado, las obras huérfanas no pueden ser usadas porque no se cuenta con la autorización del titular de derechos. Por otro, es prácticamente imposible obtener dicha autorización por lo que normalmente se termina desistiendo del uso de esas obras o las personas las usan exponiéndose a una posible sanción civil o penal ${ }^{4}$. En definitiva, y retomando el ejemplo del inicio, Google Books estaría cometiendo una ilegalidad al incluir dentro de su colección obras huérfanas ya que no ha obtenido el consentimiento previo de los titulares de los derechos que generan dichas obras 5 .

El proyecto de Google Books no ha sido la única iniciativa que da cuenta del problema que generan las obras huérfanas. Hace un par de años, los países que forman parte de la Unión Europea decidieron aprovechar la tecnología para incentivar la innovación, libre circulación de conocimiento y conservación del mismo, mediante la creación de bibliotecas digitales europeas. Este proyecto no solo incluye textos literarios, como en el caso de Google, sino que también archivos audiovisuales, música, fotografías y otros. Nuevamente, la idea de digitalizar diversos materiales fue cuestionada debido a la incertidumbre que generaba la incorporación (o posible incorporación) de obras huérfanas. El temor consistía en incurrir en una ilegalidad por el hecho de utilizar obras protegidas por la propiedad intelectual sin la debida autorización del respectivo titular.

Finalmente, a pesar de que los proyectos de digitalización masiva son una de las principales actividades que dan cuenta del problema que generan las obras huérfanas, es importante tener presente que este no es el único ámbito en que surgen cuestionamientos

\footnotetext{
${ }^{2}$ Ver http://www.google.com/googlebooks/about/history.html

${ }^{3}$ Ver declaración de AAP publishers en relación con el acuerdo que llegaron con Google luego de tener activo un juicio por 7 años por la vulneración de la propiedad intelectual, disponible en http://publishers.org/ press/85/; SAG (2012) p. 1508.

4 VAN Gompel (2012) p. 1348.

5 Ver Colangelo y Lincesso (2012) pp. 187-189; Picker (2012) p. 1268.
} 
sobre el uso de dichas creaciones ${ }^{6}$. Las obras huérfanas también pueden generar conflictos en relación con el uso tradicional de obras artísticas y literarias. Por ejemplo, eso va a suceder cuando no se sepa quiénes son los herederos de los derechos sobre una obra que se pretende adaptar. Este ejemplo sucede en la actualidad en Chile. Salvador Reyes, escritor chileno y premio nacional de literatura del año 1967 murió en 1970. Hasta el día de hoy no existe claridad sobre quiénes son sus herederos y consecuentemente no se sabe quiénes son los titulares secundarios de los derechos de propiedad intelectual que genera su obra. Debido a la falta de dicha información ha sido imposible adaptar su obra literaria para utilizarla en nuevos espacios artísticos, por ejemplo, utilizar el texto para montar una obra de teatro, una película, etc.

En definitiva, la falta de regulación sobre las obras huérfanas consolida un statu quo en el que nadie sabe cómo vincularse con las obras huérfanas, razón por la cual estas pueden ser finalmente excluidas del mercado, limitando el acceso a las mismas de parte de los usuarios $^{7}$. Esta incertidumbre es la que justifica la existencia de diversas legislaciones que tienen por objetivo asegurar el acceso a las obras huérfanas. De esta forma, se genera el desafío de establecer un mecanismo legal adecuado para permitir el acceso a las obras mencionadas.

A su vez, las regulaciones sobre las obras huérfanas plantean un desafío adicional. Toda legislación que permite el uso de las obras sin obtener la autorización previa del autor o titular de derechos, está estableciendo una restricción sobre el ejercicio de las facultades reconocidas por ley. Las restricciones al derecho de autor y derechos conexos están normadas por el derecho internacional mediante la consagración del "test de los tres pasos". Esta regla fue establecida por primera vez por el Convenio de Berna, tratado que establece tres criterios que deben ser respetados para poner restricciones al ejercicio de los derechos señalados. En primer lugar, la restricción solo puede ser aplicable a casos especiales. En segundo lugar, no puede atentar contra la explotación normal de la obra. Finalmente, tampoco puede causar un perjuicio injustificado a los intereses legítimos del autor ${ }^{8}$. Estos criterios tienen por finalidad salvaguardar los intereses de los autores o titulares de derechos, evitando que las restricciones interfieran en forma desmedida sobre el control que la ley le confiere al autor sobre su obra. Este test también ha sido recogido por otros tratados internacionales que regulan la propiedad intelectual, destacando en este contexto el ADPIC, suscrito por los países miembros de la OMC. De esta forma, toda regulación sobre obras huérfanas debe ajustarse al "test de los tres pasos".

El propósito de este artículo es dar una explicación general sobre las obras huérfanas y analizar en detalle los mecanismos legales creados en el derecho comparado para resolver la incertidumbre que genera la imposibilidad de obtener una autorización para su uso. En particular, se analizarán tres regulaciones que dan diversas respuestas a este conflicto: (1) el sistema de excepciones creado por la Directiva 2012/28/EU del Parlamento Europeo y del Consejo sobre ciertos usos autorizados de las obras huérfanas; (2) el sistema de licencias de obras huérfanas desarrollado en Canadá; y (3) el mecanismo mixto creado recientemente

\footnotetext{
6 PiCKer (2012) p. 1260.

7 Hausman y Sidak (2009) p. 429; Urban (2012) pp. 1379-1429; Picker (2012) p. 1276.

8 Artículo 9.2, Convenio de Berna.
} 
en el Reino Unido que combina un sistema de licencias colectivas ampliadas con uno de licencias de obras huérfanas. Estas tres regulaciones son un referente importante para la regulación chilena considerando que nuestra legislación no establece ningún mecanismo que intente asegurar algún tipo de uso sobre estas. Por lo mismo, es necesario estudiar tanto las ventajas como las limitaciones de las regulaciones recién individualizadas para determinar cuál sería el mecanismo adecuado para Chile, considerando tanto la regulación como la realidad chilena en relación con la propiedad intelectual.

\section{NOCIÓN GENERAL SOBRE OBRAS HUÉRFANAS}

Para tener una noción general sobre el origen de las obras huérfanas y las consecuencias de su existencia en el ámbito de la propiedad intelectual, es necesario en primer lugar hacer una breve referencia al contenido y a la lógica que rige a este ámbito del derecho.

La propiedad intelectual es una área del derecho compuesta por dos subgrupos de derechos que tienen diversos objetos de protección: el derecho de autor y derechos conexos. En el caso del derecho de autor la ley otorga protección a aquellas creaciones u obras que representan una expresión original que forma parte de los dominios artísticos, literarios o científicos $^{9}$. En el caso de los derechos conexos, la ley ampara tres tipos de objetos: (1) las producciones de los artistas, intérprete y ejecutantes; (2) los fonogramas; y (3) las emisiones realizadas por los organismos de radiodifusión. Existen varias diferencias entre ambos derechos, pero en esta oportunidad se van a resaltar ciertas similitudes que son relevantes para efecto del análisis de las obras huérfanas.

Tanto el derecho de autor como los derechos conexos consagran ciertos derechos patrimoniales en favor de los autores o titulares de derechos. Por ejemplo, se consagra la facultad de reproducir, distribuir y comunicar al público una obra protegida. La forma de ejercer estos derechos es particular ya que la ley establece garantías especiales en favor de los titulares para que tengan un control efectivo sobre la obra o prestación. En el caso del derecho de autor, la ley indica que "nadie podrá utilizar públicamente una obra del dominio privado sin haber obtenido la autorización expresa del titular del derecho de autor" ${ }^{10}$. Esto significa que ningún tercero puede utilizar una obra protegida por la propiedad intelectual salvo que cuente con una autorización expresa del titular, es decir, el titular de derechos debe realizar una declaración explícita en la que conste su voluntad de permitir el uso de la obra. A su vez, la ley señala que la persona autorizada para usar una obra no tendrá mayores derechos que aquellos contenidos en la autorización, salvo los que sean inherentes a los permitidos $^{11}$. Esta disposición consagra la independencia de las facultades que componen el derecho patrimonial, lo que significa que cada una de ellas se ejerce y explota de forma autónoma. Por ejemplo, si un tercero es autorizado para reproducir una obra esto no significa que él también pueda comunicar al público la misma ${ }^{12}$. Para realizar esta última acción,

\footnotetext{
9 Artículo 1, Ley No 17.336 de 1970.

10 Artículo 19, Ley No 17.336 de 1970.

11 Artículo 20 inciso final, Ley No 17.336 de 1970.

12 La ley $\mathrm{N}^{\circ} 17.336$ define la comunicación al público como "todo acto, ejecutado por cualquier medio o procedimiento que sirva para difundir los signos, las palabras, los sonidos o las imágenes, actualmente conocido
} 
el tercero debe contar con la autorización expresa del titular de derechos. En relación con los derechos conexos existen varias disposiciones legales que también exigen la existencia de una autorización expresa para utilizar las interpretaciones, fonogramas o emisiones realizadas por organismos de radiodifusión ${ }^{13}$. Asimismo, a pesar de que la ley nada dice en relación con la independencia de las facultades consagradas por los derechos conexos, es posible afirmar que dicha lógica también beneficia a este subgrupo de derechos.

La independencia de los derechos y la necesidad de requerir de autorización previa para utilizar una obra protegida por la propiedad intelectual no es una novedad de la regulación nacional sino que representa un principio consagrado de la regulación internacional sobre la propiedad intelectual ${ }^{14}$.

En el caso de que un tercero llegase a utilizar una obra o prestación protegida por la propiedad intelectual sin la autorización exigida por ley, su conducta podrá ser sancionada tanto por incurrir en una infracción civil como penal. En el caso de la infracción civil, dicha persona podría ser obligada a pagar una indemnización por los daños y perjuicios patrimoniales y morales causados al autor o titular de derechos ${ }^{15}$. En cuanto a la responsabilidad penal, dependiendo del uso realizado y del monto del perjuicio causado, dicha persona podría ser condenada a una pena de reclusión menor desde el grado mínimo y a una multa que fluctúa entre 5 a 1.000 unidades tributarias mensuales ${ }^{16}$.

El único argumento a favor del tercero para justificar el uso que ha hecho de una obra o prestación, y de esta forma evitar las sanciones civiles y penales antes descritas, es el de enmarcar su actuar dentro de algunas de las excepciones legales establecidas en la ley ${ }^{17}$. En todo caso, estas excepciones son específicas y están sujetas a numerus clausus por lo que si no es posible generar un vínculo con alguna de estas, el tercero no podrá legitimar su actuar.

Este es el marco legislativo dentro del que surge la problemática de las obras huérfanas. Tal como se explicó en la introducción, se entiende por obras huérfanas aquellas obras o prestaciones que están protegidas por la propiedad intelectual pero cuyo titular de derechos no puede ser localizado o identificado ${ }^{18}$. Esta definición corresponde a la consagrada en la Directiva del Parlamento Europeo sobre esta materia dictada el año 2012, y es la utilizada en este texto porque es la más comprensiva de todas. De acuerdo con esta definición, las obras huérfanas están compuestas por dos elementos. Por un lado, se aplica en aquellos casos en los que el titular de derechos no es localizable. Por otro, también se aplica cuando existen problemas en relación con la identificación del titular de derechos. La falta de identificación o localización del autor o titular de derechos genera un problema ya que en el

o que se conozca en el futuro, por el cual una pluralidad de personas, reunidas o no en un mismo lugar, pueda tener acceso a la obra sin distribución previa de ejemplares a cada una de ellas, incluyendo la puesta a disposición de la obra al público, de forma tal que los miembros del público puedan acceder a ella desde el lugar y en el momento que cada uno de ellos elija.", artículo 5 letra v).

13 Artículos 66, 67 bis, 69, Ley No 17.336 de 1970.

14 Colangelo y Lincesso (2012) p. 179.

15 Artículo 85 B, Ley No 17.336 de 1970.

${ }_{16}$ Artículos 79, 79 bis, 80, 83, 84, Ley No 17.336 de 1970.

17 Título III, Ley No 17.336 de 1970.

18 Ver artículo 2, Directiva 2012/28/UE, del Parlamento Europeo y del Consejo, de 25 de octubre de 2012. 
caso que un tercero quiera usar dicha obra o prestación le va a ser prácticamente imposible obtener la autorización expresa requerida por ley. En la medida que la ley no establezca un mecanismo adecuado para superar esta dificultad, la utilización de las obras huérfanas va a ser descartada por quienes no quieran arriesgarse a incurrir en responsabilidad civil y penal, excluyendo de tal forma la posibilidad de que otras personas tengan acceso a las mismas y que estén disponibles en el mercado ${ }^{19}$. También existen casos en los que algunos terceros prefieren asumir el riesgo de exponerse a las sanciones recién señaladas y utilizar dichas obras a pesar de que no tienen la autorización, esperando que existan mínimas posibilidades de que alguien identifique su acto como una infracción ${ }^{20}$. Algunos autores indican que normalmente las obras huérfanas están constituidas por trabajos que no tienen mucho valor comercial pero un alto interés académico y cultural, por lo que su exclusión y falta de uso constituye una pérdida considerable ${ }^{21}$.

Existen múltiples factores que pueden explicar la falta de información que existe en relación con la identificación o localización del titular del derecho ${ }^{22}$. A continuación se expondrán las principales causas:

a) Es posible que el autor o titular de derechos haya cambiado de domicilio o de números de contacto y no exista información alguna sobre su nueva dirección. Históricamente el análisis sobre los contactos se limitaba a la indicación de un domicilio pero en el día de hoy es perfectamente posible considerar otras fuentes de información para tratar de localizar al titular, tales como correo electrónico, páginas web, etc. Algunos autores señalan que obtener este tipo de información no es difícil si uno piensa en escritores, fotógrafos o artistas famosos, pero cuando el titular del derecho es una persona que no tiene esas características su localización se puede transformar en un verdadero desafío. Asimismo, la localización es difícil de realizar en aquellos casos que el titular del derecho no esté vinculado a ninguna organización de gestión colectiva de derechos, entidades que cuentan con completas bases de datos y que pueden conectarse fácilmente con sus miembros.

b) Existen casos en que la información sobre la gestión de derechos puede ser inexacta, engañosa o simplemente estar ausente. La ley sobre propiedad intelectual chilena define la información sobre la gestión de derechos como toda aquella que identifica una obra, interpretación o ejecución o fonograma, lo que incluye quien es el autor de la misma, el titular de cualquier derecho sobre la obra, interpretación o fonograma e incluso los códigos o números adjuntos a la obra que representen dicha información y que están vinculados a la puesta a disposición del objeto de protección. La inexactitud de la información se puede haber originado de varias formas. Por ejemplo, se puede haber producido por problemas de transcripción de información

\footnotetext{
19 PiCKer (2012) p. 1277.

Van Gompel (2012) p. 1348.

21 Collections Trust (2009) p. 6.

22 La identificación de las posibles hipótesis que explican la existencia de una obra huérfana se desprenden de los siguientes textos: Collections Trust (2009) p. 9; Guadamuz (2009); Ringnalda (2013) pp. 2-3.
} 
o también es posible que se hayan realizado transferencias de derechos y que la información no haya sido actualizada de forma correcta en los sistemas de registro ${ }^{23}$.

c) En algunos casos puede ocurrir que el titular de derecho no sabe que él ostenta dicha calidad por lo que no realiza esfuerzo alguno para facilitar sus contactos y consecuentemente estar disponible para otorgar autorizaciones. Esta hipótesis se puede producir cuando el titular de derechos ha muerto y no existe claridad sobre quienes son las personas que heredan sus derechos. En particular, es posible que el o los herederos desconocieran los derechos sobre la propiedad intelectual cuya titularidad recaía en el difunto y por lo tanto dichos derechos no fueron mencionados en la posesión efectiva de bienes, si es que alguna vez se realizó dicho acto.

d) Los titulares de derechos (tanto originarios como secundarios) no solo pueden ser personas naturales sino que también jurídicas. En relación con estas últimas, muchas veces sucede que la persona jurídica puede dejar de existir y es posible que no existan antecedentes claros sobre qué pasó con los derechos cuya entidad era titular. Es importante tener presente que en una industria con una larga tradición de gestión de derechos, se minimizan las posibilidades de que se generen obras huérfanas a consecuencia de la extinción de una persona jurídica, tal como sería el caso de la música ${ }^{24}$. e) Finalmente, la falta de información sobre el titular de derechos puede deberse al hecho de que la obra que se quiere utilizar no cuenta con ningún tipo de información que permita incluso saber quién es el autor de la misma. Por ejemplo, este sería el caso de fotografías o cintas de video que tienen escasas indicaciones sobre quién es su creador y por lo mismo se hace muy difícil saber por dónde se debiera tratar de buscar información sobre sus orígenes. Esta situación es cada día más común debido a que en la actualidad es muy fácil tener acceso a productos tecnológicos que permiten registrar todo tipo de imágenes por lo que prácticamente todas las personas somos potenciales creadores. A eso se debe agregar el hecho que la conexión a Internet permite que dichos registros de multipliquen indefinidamente y se comuniquen a nivel mundial lo que aumenta las dificultades de identificar al autor o titular de derechos de una obra ${ }^{25}$.

Es importante tener presente que para que una obra sea considerada como huérfana no basta con que no se tenga información sobre la localización del titular de derechos o su identificación, sino que además normalmente se exige que se hayan realizado todos los esfuerzos necesarios para obtener dicha información hasta la fecha desconocida. De tal forma, se procura impedir que se abuse de esta categoría de obras, vulnerando las facultades de titulares de derechos que eran perfectamente identificables o posibles de localizar en la medida que se hubiese realizado un mínimo esfuerzo para obtener dicha información ${ }^{26}$.

\footnotetext{
23 Artículo 85 letras a), b) y c), Ley No 17.336 de 1970.

24 Esta afirmación se sustenta en la experiencia manifestada por Jorge Mahú, Director Jurídico de la Sociedad Chilena del Derecho de Autor.

25 Ver Urban (2012) passim.

26 Pallante (2012) p. 1255.
} 


\section{AUSENCIA DE REGULACIÓN SOBRE OBRAS HUÉRFANAS EN LA LEGISLACIÓN CHILENA}

Según algunos estudios, por lo menos el 10\% de las colecciones de libros que han sido digitalizadas por Google corresponde a obras huérfanas ${ }^{27}$. Es decir, a lo menos el $10 \%$ de la colección contenida en Google Books no debería estar disponible en la página web porque se estaría vulnerando la propiedad intelectual, incluso sabiendo que dichas autorizaciones son prácticamente imposibles de obtener. Asimismo, según estudios del Reino Unido, entre un 5\% y un 10\% de las obras que forman parte de las colecciones de este país corresponderían a obras huérfanas ${ }^{28}$. De esta forma, la presencia de obras huérfanas no es un fenómeno aislado sino que constituye un porcentaje importante de las obras protegidas con las que nos relacionamos. Por lo mismo, es relevante fijar un mecanismo legal para determinar cuál es la interacción que podemos tener con estas obras dentro de la legalidad, permitiendo usarlas más allá de las excepciones o limitaciones legales y así asegurar que estas no sean olvidadas ${ }^{29}$.

A pesar de su relevancia, la legislación chilena sobre propiedad intelectual no se pronuncia sobre las obras huérfanas. Este silencio nos obliga a aplicar las normas generales sobre protección de obras y prestaciones, lo que significa que las obras que tengan las características de huérfanas deberán estar amparadas por la ley. De esta forma, no es posible usar estas obras en la medida que no se cuente con la autorización expresa del autor o titular de derechos, salvo que el acto que se quiera realizar pueda ser vinculado con alguna de las excepciones legales contempladas en la ley No 17.336 .

Al mencionar la ley chilena sobre propiedad intelectual es importante hacer una aclaración. Las obras huérfanas no deben ser confundidas con las obras de autor desconocido, las que forman parte del dominio público, ni con las obras anónimas.

El artículo 11 de la ley No 17.336 regula las obras que forman parte del patrimonio cultural común o dominio público. Estas obras se caracterizan por estar a libre disposición de las personas, es decir, no se requiere de autorización previa del autor o titular de derechos para utilizarlas. El propósito del patrimonio cultural común es asegurar el acceso al conocimiento y fortalecer un ambiente social democrático y político mediante el libre uso de las creaciones humanas ${ }^{30}$. La ley fija 5 categorías de obras que forman parte del dominio público, siendo las obras cuyo plazo ha expirado la más conocida de todas ${ }^{31}$.

\footnotetext{
27 Hausman y Sidak (2009) p. 420, Ver también SAG (2012) passim.

28 Collections Trust (2009) p. 18.

29 Algunos teóricos del derecho comparado indican que el uso de las obras huérfanas se puede resolver recurriendo al sistema de excepciones del copyright conocido como fair use. Este argumento no es aplicable en el caso chileno debido a que el régimen de excepciones, tal como se señaló con anterioridad, es un sistema de numerus clausus, lo que significa que solo se pueden utilizar las hipótesis expresamente individualizadas sin poder extender su aplicación a escenarios no contemplados en la ley. Urban (2012) passim; SAG (2012) passim.

30 Davies (1994) p. 91; Macmillan (2007) p. 112.

31 Por regla general, "la protección otorgada por esta ley dura por toda la vida del autor y se extiende hasta por 70 años más, contados desde la fecha de su fallecimiento”, artículo 10 inciso primero, ley № 17.336 de 1970 .
} 
Una segunda categoría de obras que forman parte de dominio público son aquellas "de autor desconocido, incluyéndose las canciones, leyendas, danzas y las expresiones del acervo folclórico" (artículo 11 letra b) Ley No 17.336) ${ }^{32}$. Es necesario hacer especial mención a esta categoría ya que en principio pareciera ser similar a la última clase (e) de situaciones mencionada en la sección anterior que configuran las obras huérfanas -obras sobre las que no se cuenta con información que permita identificar al autor de la misma-. Claro está que una obra no puede ser huérfana y al mismo tiempo pertenecer al patrimonio cultural común. Esto se debe a que las obras huérfanas están protegidas por la propiedad intelectual, por lo que se requiere de autorización previa para ser utilizadas por terceros. En cambio, las obras que forman parte del patrimonio cultural común ya no está protegidas, por lo que pueden ser utilizadas sin requerir autorización previa de ninguna persona ${ }^{33}$.

La extensión del contenido del artículo 11 letra b) de la Ley No 17.336 ha sido objeto de análisis en la doctrina nacional. En principio se podría pensar que dicha categoría incluye todas las obras de autor desconocido y que la ley da como ejemplo los casos de expresiones del acervo folclórico. En ese caso, tendríamos que excluir la clase (e) de las hipótesis que configuran las obras huérfanas ya que la ley habría optado por considerar las obras de autor desconocido como parte del dominio público. Varios autores nacionales defienden una interpretación restrictiva del artículo 11 letra b), indicando que dicha disposición agrupa a todas las obras del folclore en las que no exista autor conocido ${ }^{34}$. Por ejemplo, la leyenda del Caleuche sería una obra que quedaría amparada por esta regulación ya que corresponde a una obra de tradición folclórica de Chile y no se conoce al autor que haya dado origen a la misma. Lo relevante para la discusión sobre las obras huérfanas es entender que en el caso de estas sí existe un autor que se vincula a una obra, pero el problema es que objetivamente él, o el titular de derechos en el supuesto que no sean la misma persona, no es identificable. De esta forma, las obras huérfanas no pueden ser confundidas con la categoría de obras de autor desconocido.

Las obras anónimas son la segunda categoría de obras que debe ser diferenciada de las huérfanas. La ley No 17.336 las define como "aquella en que no se menciona el nombre del autor, por voluntad del mismo, o por ser este ignorado" ${ }^{35}$. Un clásico ejemplo de obras anónimas de la literatura nacional es el libro “Los Versos del Capitán”, el que originalmente fue publicado como obra anónima y que con posterioridad Pablo Neruda reconoció su autoría sobre el mismo. El tratamiento legal de las obras anónimas se diferencia del aplicable a las obras de autor desconocido. En principio, las obras anónimas están amparadas por la propiedad intelectual. De esta forma, existen derechos morales y patrimoniales que emanan de la misma. Ahora bien, transcurrido el plazo de protección regulado por ley, las obras anónimas pasarán a formar parte del dominio público o patrimonio cultural común. Tal

32 Artículo 11 b), Ley No 17.336 de 1970.

33 Esta distinción entre obras huérfanas y obras que forman parte del patrimonio cultural común se basa en la vigencia de los derechos patrimoniales que otorga el derecho de autor. Esto se debe a que los derechos morales son perpetuos y por lo tanto estos se mantienen vigentes aun cuando las obras pasan a formar parte del patrimonio cultural común.

34 Ruiz Gallardo (2008) p. 50. Walker Echenique (2014) p. 135.

35 Artículo 5, letra d), ley No 17.336 de 1970. 
como en el caso de las obras de autor desconocido, las obras huérfanas se diferencian de las obras anónimas en el hecho de que en las primeras sí existe un autor que se vincula a una obra, pero él, o el titular de derechos en el supuesto que no sean la misma persona, no es identificable.

\section{DIVERSOS TIPOS DE REGULACIONES QUE PERMITEN USAR LAS OBRAS HUÉRFANAS}

Luego de exponer una noción general sobre qué debe entenderse por obra huérfana y los problemas que conlleva su existencia, es necesario analizar las diferentes regulaciones que hasta la fecha se han establecido para permitir su uso, de tal modo que sea posible tomarlas como referencia al momento que se decida regular esta materia en Chile ${ }^{36}$.

\section{RÉGIMEN DE EXCEPCIONES LEGALES PARA EL USO DE UNA OBRA HUÉRFANA}

Una de las pocas regulaciones que existen sobre el uso o explotación de las obras huérfanas corresponde a una Directiva del Parlamento Europeo que fue dictada el 25 de octubre del $2012^{37}$. Esta Directiva se caracteriza por establecer un régimen de excepciones legales que permitirían el uso de una obra huérfana sin requerir la autorización previa del titular o de alguna entidad facultada para otorgarla.

Antes de analizar los elementos principales que componen dicha regulación, es interesante resaltar las motivaciones o intereses que dieron origen a la misma. En los conside-

\footnotetext{
36 Para analizar las regulaciones existentes sobre obras huérfanas es relevante identificar los criterios que en el año 2007 fueron fijados de forma conjunta por la Asociación Internacional de Editores (Internacional Publishers Association - IPA) y la Federación Internacional de Asociaciones de Bibliotecas e Instituciones (International Federation of Library Associations and Institutions - IFLA), para facilitar el uso sobre las mismas. Estas organizaciones fueron una de las primeras en tener la iniciativa de fijar criterios universales para resolver el problema de las obras huérfanas, permitiendo por un lado que estas sean usadas, y de esa forma satisfacer el interés público comprometido, pero al mismo tiempo protegiendo las facultades de los autores o titulares de derechos. Los criterios enunciados por estas organizaciones son 5 . En primer lugar, se requiere que se realicen diligencias adecuadas para tratar de ubicar al titular de derechos. Entre otras cosas, estas diligencias deben realizarse de buena fe y deberían consultarse múltiples fuentes para asegurar que la información obtenida sea fidedigna. En segundo lugar, si la obra huérfana va a ser usada, se requiere que siempre se identifique al titular de derechos sobre dicha obra, salvo que no se conozca la identidad del mismo. En tercer lugar, se le debe permitir al titular de derechos obtener la restitución de sus facultades una vez que este haya sido localizado o identificado. Como consecuencia de lo anterior, también se le debe otorgar una remuneración razonable por el uso que se haya hecho de la obra huérfana durante el tiempo que el titular no pudo ser contactado. En cuarto lugar, toda regulación que permita usar las obras huérfanas bajo ciertas condiciones debe ser los suficientemente flexible para amparar a los usuarios de buena fe, en especial considerando los esfuerzos creativos y la inversión realizada. Finalmente, la autorización para usar una obra huérfana no debería ser exclusiva, por lo que un usuario solo podrá oponerse al trabajo realizado por un tercero en la medida que dicho trabajo afecte los derechos que genera la obra derivada, pero no la obra huérfana.

Tal como se verá más adelante, los tres modelos de regulación que son analizados en este trabajo satisfacen en mayor o menor medida los criterios establecidos en conjunto por IPA y IFLA. Ver IFLA/IPA Joint Statement on Orphan Works disponible en http://www.ifla.org/publications/iflaipa-joint-statement-on-orphan-works.

37 Directiva 2012/28/EU del Parlamento Europeo y del Consejo sobre ciertos usos autorizados de las obras huérfanas. Disponible en http://eur-lex.europa.eu/LexUriServ/LexUriServ.do?uri=OJ:L:2012:299:0005:0012:E s:PDF (acceso 29 de mayo 2013).
} 
randos que fundamentan la Directiva, en primer lugar se destaca la labor que realizan las bibliotecas, archivos y diversos organismos de conservación para digitalizar sus colecciones y así crear bibliotecas digitales europeas ${ }^{38}$. En particular se señala que esta labor contribuye a la conservación y difusión del patrimonio cultural europeo ${ }^{39}$. Tal como se verá cuando se analice la Directiva, la labor desarrollada por estos organismos de conservación es clave para entender el ámbito de la aplicación de la regulación, constituyendo un conjunto de normas que finalmente tienen por objetivo justamente facilitar esta actividad de conservación, sin pretender extenderse más allá de lo estrictamente necesario para permitir la concreción de dicha labor.

A su vez, este trabajo de conservación es valorado por el Parlamento Europeo debido a que se considera como un elemento que impulsa la libre circulación de conocimiento y de innovación. En este sentido, la Directiva pretende regular el uso de las obras huérfanas para eliminar obstáculos que impidan u obstruyan el acceso a la información y consecuentemente el desarrollo de la innovación ${ }^{40}$. También se indica que el afán de promover la innovación no es considerado como un factor que se contraponga con la regulación sobre propiedad intelectual. La Directiva expresamente indica el derecho de autor constituye el fundamento económico de la industria o sector creativo, estimulando la innovación, creación, producción e inversión ${ }^{41}$. De tal manera, es posible afirmar que bajo la lógica de la Directiva, la regulación sobre uso de obras huérfanas no se opone a los fundamentos de la propiedad intelectual sino que lo complementa. Por lo mismo, dicha regulación parte de la base que a los titulares de derechos se les debe reconocer el derecho exclusivo de usar sus obras, pero que el problema que surge con las obras huérfanas es justamente la imposibilidad de obtener dicho consentimiento ${ }^{42}$.

Finalmente, la Directiva indica que la regulación sobre uso de obras huérfanas no solo se sustenta en razones de preservación o conservación, sino que la incertidumbre que generan también produce obstáculos en el funcionamiento del mercado interno, en especial por las diferencias de planteamientos que pueden surgir acerca de su accesibilidad y uso. Esto es especialmente problemático desde la perspectiva del mercado europeo ya que este depende en gran medida de la seguridad jurídica y de la homogeneización sobre la regulación de los bienes que se transan internamente. De esta manera, a través de esta regulación se busca asegurar que el uso de obras huérfanas sea uniforme ${ }^{43}$.

38 Ver Colangelo y Lincesso (2012) pp. 192-195.

39 Considerando 1, Directiva 2012/28/EU del Parlamento Europeo y del Consejo sobre ciertos usos autorizados de las obras huérfanas.

${ }^{40}$ Considerando 2, Directiva 2012/28/EU del Parlamento Europeo y del Consejo sobre ciertos usos autorizados de las obras huérfanas.

${ }^{41}$ Considerando 5, Directiva 2012/28/EU del Parlamento Europeo y del Consejo sobre ciertos usos autorizados de las obras huérfanas.

${ }^{42}$ Considerando 6-7, Directiva 2012/28/EU del Parlamento Europeo y del Consejo sobre ciertos usos autorizados de las obras huérfanas.

43 Considerando 8-9, Directiva 2012/28/EU del Parlamento Europeo y del Consejo sobre ciertos usos autorizados de las obras huérfanas. 
Existen tres elementos interesantes para analizar en relación con esta regulación: (a) fija excepciones cuya aplicación es limitada en cuanto al tipo de obras que quedan afectas a ese beneficio, uso que se puede realizar y quiénes están autorizados a desarrollar dicha actividad; (b) establece la obligación de la creación de un registro de obras huérfanas y; (c) exige que el reconocimiento del estatus de obra huérfana sea revocable en la medida que el titular de los derechos de autor o conexos reclame sus derechos sobre la obra o prestación y además se le compense económicamente por el uso realizado sobre la misma.

a. La excepción de uso es de aplicación restringida

Tal como se señaló con anterioridad, la Directiva del Parlamento Europeo regula las excepciones en favor de ciertos usuarios y bajo ciertas condiciones. En cuanto a las entidades que están facultadas para beneficiarse de estas excepciones, la Directiva expresamente señala que su regulación beneficiará a las bibliotecas, centros de enseñanza y museos, accesibles al público, así como archivos, organismos de conservación del patrimonio cinematográfico o sonoro y organismos públicos de radiodifusión, establecidos en los Estados miembros de la Unión Europea ${ }^{44}$. En consecuencia, la aplicación de esta excepción no se extiende a todo tipo de persona, ya sea natural o jurídica, que estén interesadas en usar una obra huérfana. Por ejemplo, es posible afirmar que la compañía Google no calificaría para beneficiarse de la excepción legal ya que su naturaleza jurídica, y en especial su función, no corresponde a ninguna de las entidades contenidas en la lista taxativa de la Directiva.

A su vez, la aplicación de la excepción sobre uso de obras huérfanas es restringida ya que solamente se puede utilizar en relación con obras protegidas por el derecho de autor que estén contenidas en un formato específico o ciertas prestaciones vinculadas a los derechos conexos. Junto con señalar otros requisitos específicos, la Directiva realiza tres distinciones para identificar su ámbito de aplicación. Primero, indica que la excepción será aplicable a todas aquellas "obras publicadas en forma de libros, revistas especializadas, periódicos, revistas y otro material impreso que figuren en las colecciones de bibliotecas, centros de enseñanza o museos accesibles al público, así como en las colecciones de archivos o de organismos de conservación del patrimonio cinematográfico o sonoro" ${ }^{45}$. De esta forma, la Directiva no se aplica a obras tales como mapas, fotografías, dibujos o planos, salvo que estos estén contenidos en alguna de las obras individualizadas con anterioridad, como por ejemplo, un libro ${ }^{46}$. Segundo, la excepción también se aplica a las "obras cinematográficas o audiovisuales y fonogramas que figuren en las colecciones" de las entidades recién nombradas ${ }^{47}$. Tercero, la regulación incluye a las "obras cinematográficas o audiovisuales y los

\footnotetext{
44 Artículo 1, Directiva 2012/28/EU del Parlamento Europeo y del Consejo sobre ciertos usos autorizados de las obras huérfanas.

45 Artículo 1, letra a) Directiva 2012/28/EU del Parlamento Europeo y del Consejo sobre ciertos usos autorizados de las obras huérfanas.

46 Deazley y Stobo, Victoria (2013) p. 40.

47 Artículo 1, letra b) Directiva 2012/28/EU del Parlamento Europeo y del Consejo sobre ciertos usos autorizados de las obras huérfanas.
} 


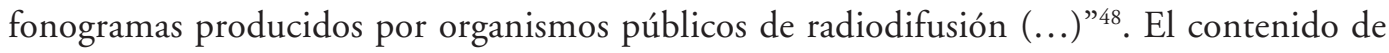
esta restricción es entendible al recordar que una de las motivaciones de la Directiva es la de eliminar obstáculos legales para permitir el trabajo de digitalización que están haciendo las bibliotecas, archivos y organismos de conservación con la finalidad de preservar el patrimonio cultural europeo. Es decir, la lista simplemente intenta abarcar la actividad de digitalización que hasta la fecha han realizado esos organismos, sin generar mayores innovaciones al respecto o legitimar dicha actividad más allá de ese espectro.

En cuanto a los tipos de usos que abarca la excepción regulada en la Directiva, esta también es restrictiva. La Directiva solo autoriza a las entidades identificadas con anterioridad a usar las obras huérfanas de dos maneras: (a) reproducción y; (b) comunicación al público y puesta a disposición del público ${ }^{49}$. Finalmente, la Directiva señala que los usos autorizados deberán ser efectuados con el fin de alcanzar objetivos relacionados con la misión de interés público que tienen las entidades beneficiadas con el régimen de excepción ${ }^{50}$. Esto significa que incluso dentro de los limitados usos que permite la Directiva en relación las obras huérfanas, las entidades no pueden realizar cualquier tipo de actividad sino que el uso debe estar justificado en razón de la misión de interés público que tienen estas entidades. El alcance de esta disposición deberá ser aclarado en la medida que surjan dudas en cuanto su aplicación o implementación. En todo caso, la propia Directiva contiene en sus considerandos algunos criterios que podrían dar cuenta del objetivo que debe estar detrás de esta "misión de interés público". Por ejemplo, es posible suponer que la conservación y difusión del patrimonio cultural europeo podría ser un objetivo satisfactorio.

\section{b. Creación de un registro de obras huérfanas}

Junto con delimitar el alcance de la excepción sobre usos de obras huérfanas, la Directiva establece que los Estados miembros deberán asumir la obligación de crear un registro único sobre las mismas. Este registro debe consistir en una base de datos abierta al público, cuya información será proveída por las investigaciones que realicen las entidades facultadas para beneficiarse de la excepción de uso, junto con los archivos que deberán elaborar en relación con dicha gestión. Es decir, la información será otorgada por las bibliotecas, centros de enseñanza y museos, accesibles al público, entre otros.

Por un lado, la recopilación y puesta a disposición del público de estos antecedentes facilitará la homogeneización o reconocimiento mutuo en cuanto a la identificación de obras huérfanas, esto considerando que la Directiva señala que toda obra que sea considerada huérfana en un Estado miembro deberá también ser considerada como tal en todos los Estados miembros ${ }^{51}$. Por otro, también se indica que este registro puede cumplir un rol

\footnotetext{
48 Artículo 1, letra c) Directiva 2012/28/EU del Parlamento Europeo y del Consejo sobre ciertos usos autorizados de las obras huérfanas.

49 Artículo 6, Directiva 2012/28/EU del Parlamento Europeo y del Consejo sobre ciertos usos autorizados de las obras huérfanas.

50 Artículo 1, Directiva 2012/28/EU del Parlamento Europeo y del Consejo sobre ciertos usos autorizados de las obras huérfanas.

51 Artículo 4, Directiva 2012/28/EU del Parlamento Europeo y del Consejo sobre ciertos usos autorizados de las obras huérfanas.
} 
importante para la prevención de posibles infracciones a la propiedad intelectual, especialmente considerando que la identificación de una obra como huérfana no tiene carácter permanente sino que la Directiva asegura que el titular pueda reclamar sus derechos y poner término a este tipo de uso excepcional ${ }^{52}$. Esta noción de prevención confirma el hecho de que la Directiva intenta corregir el problema que genera la identificación de una obra como huérfana en cuanto a su explotación, sin pretender afectar el marco de aplicación de la regulación sobre propiedad intelectual.

\section{c. Fin de la condición de obra huérfana}

Finalmente, tal como fue recién señalado, la Directiva se preocupa de no otorgar un carácter permanente a la condición de una obra como huérfana, permitiendo en todo momento que el titular de derechos pueda reclamar su condición de tal y consecuentemente poner fin a dicha calificación, recuperando el control total sobre sus facultades ${ }^{53}$. Asimismo, la regulación indica que el titular de derecho podrá obtener una compensación equitativa por el uso al que fue sometida su obra o prestación durante el tiempo que transcurrió desde que fue declarada obra huérfana hasta que se reclamaron derechos sobre la misma ${ }^{54}$. Nuevamente, esta disposición da cuenta del interés que existe de parte del Parlamento Europeo de armonizar los intereses envueltos.

\section{RÉGIMEN DE LICENCIAS SOBRE OBRAS HUÉRFANAS}

A diferencia de la regulación del Parlamento Europeo, la disposición sobre obras huérfanas contenida en la regulación canadiense sobre propiedad intelectual no es reciente. Esta data de 1988 y ha tenido mínimos ajustes desde esa fecha. En este caso, las personas interesadas en usar una obra huérfana deberán solicitar una autorización especial a un tribunal administrativo, por lo que es necesario seguir un procedimiento particular y obtener una resolución que faculta al solicitante a usar esa obra, evitando que este incurra en responsabilidades civiles o penales.

La regulación canadiense faculta al tribunal administrativo a otorgar licencias en aquellos casos en los que se han hecho esfuerzos razonables para localizar al titular de los derechos y este no ha podido ser ubicado ${ }^{55}$. Estadísticas demuestran que la exigencia de la realización de este esfuerzo genera un impacto positivo sobre la situación de las obras huérfanas. En el caso de Canadá, alrededor de un 22\% de las solicitudes que fueron abandonadas se debió al hecho de que el titular de derechos pudo ser localizado ${ }^{56}$. Según la doctrina y la jurisprudencia del propio tribunal administrativo, la licencia de uso de obras huérfanas solo puede ser otorgada en aquellos casos en que la locación del titular es desconocida, no pudiendo ser ex-

\footnotetext{
52 Considerando 16, Directiva 2012/28/EU del Parlamento Europeo y del Consejo sobre ciertos usos autorizados de las obras huérfanas

53 Artículo 5, Directiva 2012/28/EU del Parlamento Europeo y del Consejo sobre ciertos usos autorizados de las obras huérfanas.

54 Artículo 6.5, Directiva 2012/28/EU del Parlamento Europeo y del Consejo sobre ciertos usos autorizados de las obras huérfanas.

55 Sección 77.1 Copyright Act. (R.S.C 1985, c. C-42) Canadá.

56 De Beer y Bouchard (2009) p. 33.
} 
tendida a otras hipótesis que pueden ser vinculadas con las obras huérfanas, como por ejemplo el caso en que no exista claridad sobre quien es el titular de los derechos ${ }^{57}$.

Es común que una misma solicitud de licencia contenga la individualización de múltiples obras huérfanas. El tribunal puede otorgar licencias sobre todas estas en la medida que lo estime adecuado siempre cuando todas ellas estén debidamente individualizadas y se pruebe que para cada una de ellas se ha realizado la búsqueda del titular de derechos y que esta ha sido infructuosa ${ }^{58}$.

\section{a. Ámbito de aplicación de la licencia sobre obras huérfanas}

En cuanto al ámbito de aplicación de la licencia es necesario analizar tres factores. En primer lugar, se debe estudiar el objeto de la licencia. La regulación señala que la licencia puede ser otorgada tanto sobre obras protegidas por el derecho de autor como sobre fonogramas, interpretaciones o ejecuciones, y radiodifusión. Según algunos estudios, la mayoría de las solicitudes para obtener la licencia de uso de obras huérfanas están vinculadas a obras literarias, artísticas, musicales, fonogramas e interpretaciones ${ }^{59}$.

La ley establece ciertos requisitos para que esta licencia sea aplicable. En el caso de las obras protegidas por el derecho de autor y de los fonogramas, se exige que la obra haya sido publicada. Para tener una idea del contenido de esta exigencia, es posible señalar que la regulación chilena entiende por publicación de una obra la oferta al público de la misma mediante ejemplares tangibles ${ }^{60}$. En cuanto a las interpretaciones o ejecuciones y la radiodifusión, la regulación canadiense señala que debe existir una fijación de los mismos ${ }^{61}$. Es decir, y nuevamente haciendo referencia a la legislación chilena, solo se podrá obtener una licencia de uso en la medida que dichos trabajo estén contenidos en un dispositivo que permita su reproducción, percepción y comunicación ${ }^{62}$. De esta forma, no basta con que una obra o trabajo esté protegido por la propiedad intelectual para que el tribunal administrativo pueda otorgar una licencia de uso, sino que, dependiendo de la naturaleza del trabajo, se exige además su publicación o fijación. Claramente, el ámbito de aplicación de esta regulación es más extenso que la excepción establecida por el Parlamento Europeo ya que la ley canadiense identifica ciertas características que deben satisfacer las obras o prestaciones que pueden ser objeto de la licencia (publicación o fijación) pero no limita dichas obras a un cierto contexto, tal como lo hace la Directiva al exigir un vínculo con instituciones tales como bibliotecas, centros de enseñanza o museos, accesibles al público.

En segundo lugar, se debe estudiar quien puede ser beneficiado por esta licencia. La regulación canadiense no establece limitaciones en relación a quienes son las personas facultadas para pedir esta licencia. De esta forma, la licencia puede ser solicitada tanto por personas naturales como jurídicas y además pueden tener múltiples propósitos. Esto queda

\footnotetext{
57 De Beer y Bouchard (2009) p. 16.

58 Deazley y Stobo (2013) p. 35.

59 De Beer y Bouchard (2009) p. 4.

60 Artículo 5 letra o, Ley No 17.336 de 1970.

61 Sección 77.1 Copyright Act. (R.S.C 1985, c. C-42) Canadá.

${ }^{62}$ Artículo 5 letra v, Ley No 17.336 de 1970.
} 
claro al analizar el perfil de personas que han solicitado este tipo de licencias. La gran mayoría de las licencias son pedidas por organizaciones comerciales o de negocios, seguidas por individuos, instituciones educacionales, galerías museos y organizaciones de caridad o comunitarias $^{63}$. Nuevamente, esta amplitud marca una diferencia con la regulación contenida en la Directiva, en la que solo se autoriza a ciertos organismos para beneficiarse de la excepción legal, todos ellos vinculados de una u otra forma a actividades de conservación patrimonial.

En tercer lugar, la regulación canadiense no establece limitación alguna en cuanto a los usos que pueden ser autorizados, sino que simplemente hace referencia a la regulación general que beneficia a las obras protegidas por el derecho de autor y derechos conexos. De esta forma, el tribunal administrativo puede autorizar el ejercicio de todas las facultades que forman parte del derecho patrimonial permitiendo, por ejemplo, se pueda permitir tanto la reproducción como la modificación de la obra huérfana para la creación de una obra derivada. La extensión de este tipo de autorizaciones también constituye una diferencia substancial en comparación con la regulación del Parlamento Europeo ya que las excepciones solamente permiten la reproducción y comunicación al público de la obra huérfana.

\section{b. Condiciones para el uso de la obra huérfana}

La regulación canadiense faculta al tribunal administrativo a establecer condiciones en relación con el uso que se pueda hacer de la obra huérfana en cuestión ${ }^{64}$. Existen dos condiciones que están expresamente señaladas en la regulación canadiense, pero el tribunal es libre de agregar nuevas. En primer lugar, la ley exige que la licencia no sea exclusiva, de tal forma que no es posible impedir que terceros usen la misma obra huérfana para otros propósitos $^{65}$. En segundo lugar, la ley exige que el tribunal establezca una tarifa por el uso de dicha obra $^{66}$. El monto de la tarifa no ha sido regulado en la ley por lo que el tribunal normalmente recurre a las sociedades de gestión colectiva para estudiar el criterio adecuado para fijar una tarifa particular, junto con la realización de estudios de mercado cuando sea considerado necesario. De la misma forma, el tribunal ha hecho una interpretación extensiva de esta facultad y en algunos casos se han establecido tarifas que son simbólicas y que no representan una carga monetaria como también existen casos en los que no se exige el pago inmediato de la tarifa, sino que se condiciona a que el titular de derechos sea localizado ${ }^{67}$.

En cuanto a la gestión de los recursos que se recaudan por concepto del pago de la tarifa, es interesante destacar que ha existido una evolución sobre esta materia. La ley establece que el titular de derechos puede, dentro de otras cosas, reclamar el pago de la tarifa que fue fijada en la licencia dentro de un plazo de 5 años $^{68}$. Para cumplir con esta disposición originalmente se exigía que las sociedades de gestión colectiva retuvieran el

\footnotetext{
3 De Beer y Bouchard (2009) p. 4.

64 Sección 77.2 Copyright Act. (R.S.C 1985, c. C-42), Canadá.

65 Sección 77.2 Copyright Act. (R.S.C 1985, c. C-42), Canadá.

66 Sección 77.3 Copyright Act. (R.S.C 1985, c. C-42), Canadá.

67 De Beer y Bouchard (2009) pp. 24-26.

68 Sección 77.3 Copyright Act. (R.S.C 1985, c. C-42), Canadá.
} 
dinero pagado por el concepto de tarifa hasta por un plazo de 5 años. Luego de expirado dicho plazo, las sociedades podían disponer de esos recursos como quisieran. Este sistema fue modificado luego que se considerara que el sistema era muy engorroso, especialmente considerando que las sumas de dinero que administraba no eran muy altas. Por lo mismo, hoy en día se faculta a las sociedades de gestión colectiva a usar dichos recursos pero con la obligación de restituirlos a los titulares de derechos una vez que estos sean localizados dentro del plazo de 5 años desde que se otorgó la licencia ${ }^{69}$.

A pesar de que no están señaladas expresamente en la ley, existen otras dos condiciones que normalmente forman parte de las licencias de uso de una obra huérfana. El tribunal administrativo generalmente señala que la licencia de uso de obras huérfanas solo tendrá efectos dentro del territorio nacional de Canadá, estableciendo de tal forma una restricción territorial sobre el ámbito de aplicación de la licencia. Asimismo, el tribunal suele establecer un límite en cuanto a la duración de la licencia, el que generalmente no va a ser menor de 5 años, ya que se toma como referencia el plazo que tiene el titular de derechos para exigir la restitución del dinero que fue pagado por concepto de la tarifa ${ }^{70}$.

Finalmente, es interesante destacar que según la regulación canadiense, el tribunal administrativo puede otorgar una licencia, lo que implica que dicha entidad tiene un margen de discrecionalidad para evaluar los antecedentes que se le presentan al solicitarse dicha licencia, sin estar obligada a conceder la misma ${ }^{71}$. En todo caso, han sido muy pocos los casos en los que este organismo ha rechazado una solicitud que cumple con todas las exigencias formales ${ }^{72}$. Además, la doctrina indica que la labor que realiza esta entidad queda sujeta a las exigencias propias de todo organismo administrativo por lo que la discrecionalidad debe ser ejercida de forma razonable ${ }^{73}$.

\section{c. Reivindicación de la obra huérfana}

La regulación canadiense no señala expresamente que el titular de derechos puede reivindicar sus facultades sobre la obra huérfana. A pesar de lo anterior, es evidente que el titular de derechos puede reivindicar su calidad de tal ya que en la medida en que él se identifique y vincule con la obra, esta dejará de ser obra huérfana y por lo tanto no le será aplicable este régimen especial de licencias. En todo caso, no existe claridad si el titular de derechos está facultado para revocar una licencia que ha sido previamente otorgada por el tribunal administrativo de acuerdo a las facultades que le otorga la ley ${ }^{74}$. A pesar de esta incertidumbre el titular de derechos, por lo menos, puede tener la certeza de poder reclamar el pago de la tarifa que fue fijada por el tribunal y que dicha licencia va a expirar cuando se cumpla el plazo que fue fijado por la misma entidad, por lo que va a llegar un momento en que el tercero no va a poder seguir utilizando la obra o prestación en cuestión.

\footnotetext{
69 De Beer y Bouchard (2009) p. 26.

70 De Beer y Bouchard (2009) pp. 22-27.

71 Sección 77.1.d Copyright Act. (R.S.C 1985, c. C-42), Canadá.

72 De Beer y Bouchard (2009) p. 3.

73 De Beer y Bouchard (2009) p. 20.

74 De Beer y Bouchard (2009) p. 30.
} 


\section{Sistema MiXTo DE RÉGIMEN DE LICENCIAS SObRE ObRAS HUÉRFANAS Y LiCENCIAS COLECTIVAS AMPLIADAS}

Recientemente, el Reino Unido ha dictado una regulación especial para dar solución al problema que generan las obras huérfanas. Esta regulación se fundamenta en la necesidad de reconocer la importancia de la propiedad intelectual, particularmente como elemento clave de la estructura social y económica de este país y como sistema que permite a los autores y artistas vivir de su trabajo, pero al mismo tiempo procurar que esta protección no impida el uso o acceso de las obras por terceros ${ }^{75}$.

La regulación se caracteriza por consagrar un sistema mixto compuesto por tres elementos. En primer lugar, el Reino Unido establece un régimen de licencias que puede llegar a ser similar al canadiense. Se autoriza al Secretario de Estado a regular este tipo de licencias, quien deberá señalar quiénes son las personas que estarán habilitadas para autorizar el uso de obras huérfanas. De acuerdo al Enterprise and Regulatory Reform Act 2013, para estos efectos se entiende por obra huérfana aquella cuyo titular del derecho no ha podido ser localizado, pero la licencia también es aplicable en el caso que no exista seguridad se subsisten o no los derechos de autor o que existan dudas sobre quién es el supuesto titular de derechos. La ley expresamente señala que la licencia otorgada no puede ser exclusiva y que los efectos que produce la licencia son los mismos que se hubiesen producidos si esta hubiese sido otorgada por el titular de derechos ${ }^{76}$. El organismo administrativo que concede la autorización a terceras personas para utilizar la o las obras huérfanas exige que se hayan realizado los esfuerzos necesarios para localizar al titular de derechos. Este tipo de licencia se puede conceder tanto para uso no comercial como uso comercial de obras huérfanas y la entidad administrativa debe fijar una tarifa que se deberá cobrar por el uso de la obra, la que deberá beneficiar al titular de derechos en la medida que en el futuro sea identificado o localizado ${ }^{77}$. De esta forma, esta licencia es similar a la regulada en Canadá.

En segundo lugar, también se consagra la obligación de crear un registro de obras que han sido catalogadas como huérfanas. La principal función de este registro es consagrar una herramienta de búsqueda que permita al titular de derechos saber que su obra o prestación ha sido catalogada como huérfana y de esa forma ser capaz de reclamar su condición de titular y volver a obtener el control sobre la explotación de la misma ${ }^{78}$. En este sentido, el sistema de registro se asimila al establecido por la Directiva del Parlamento Europeo.

En tercer lugar, la regulación consagra un sistema de licencias colectivas ampliadas (LCA). Este sistema de licencias requiere de mayor análisis así es que a continuación será explicado con detalle.

\footnotetext{
75 Government Policy Statement: Consultation on Modernising Copyright (2011) disponible en http://www. ipo.gov.uk/response-2011-copyright.pdf (acceso 1 de Julio 2013) p. 5.

76 Section 77, Enterprise and Regulatory Reform Act 2013.

77 Enterprise and Regulatory Reform Act 2013 policy paper (2013) disponible en https://www.gov.uk/ government/uploads/system/uploads/attachment_data/file/206078/bis-13-905-enterprise-and-regulatoryreform-act-2013-policy.pdf (acceso 19 de Junio 2013), p. 33.

78 Enterprise and Regulatory Reform Act 2013 policy paper (2013) p. 34.
} 


\section{a. Licencias colectivas ampliadas}

Las LCAs son nuevas en el Reino Unido y su incorporación en el sistema del copyright no se limita únicamente al uso de obras huérfanas pero perfectamente puede involucrarlas. Estas licencias normalmente son administradas por las sociedades de gestión colectiva.

En principio, las sociedades de gestión colectiva solo están autorizadas para otorgar licencias colectivas que permitan el uso de las obras o prestaciones que forman parte de su repertorio, es decir, obras o prestaciones cuya titularidad corresponda a los miembros de la sociedad colectiva. De esta forma, la entidad normalmente no está facultada para conceder autorizaciones sobre material cuyos titulares no sean miembros de la organización ya que ellos no la han facultado para gestionar los derechos que generan sus obras o prestaciones. La LCA modifica esta limitación legal, permitiendo que las sociedades de gestión colectiva otorguen licencias colectivas incluso sobre obras que no forman parte de su repertorio. Esto significa que la licencia se aplicará sobre todas las obras o prestaciones de una área determinada, como por ejemplo, obras literarias, audiovisuales, musicales, plásticas, etc, sin importar si los titulares de derechos son miembros o no de la sociedad, son nacionales o extranjeros, incluso si son conocidos o no han podido ser identificados o si se sabe cuál es su locación o esta se desconoce ${ }^{79}$.

Estas licencias deben ser voluntarias, lo que significa que las personas que no son miembros de la sociedad de gestión colectiva no pueden ser obligadas a formar parte de esta licencia. De lo contrario, estas licencias se transformarían en un régimen forzoso de administración de derechos. Por lo mismo, se crea un sistema opt-out, mediante el cual, a pesar de que en principio la obra de los titulares que no son miembros de las sociedades de gestión colectiva formará parte de la licencia que otorgue dicha entidad, con posterioridad el titular tiene la posibilidad de excluir el uso de su obra de la licencia que fue otorgada. De esta forma, todo titular de derechos que no quiere que su obra forme parte de la licencia colectiva podrá ejercer su derecho a ser excluido de dicha autorización ${ }^{80}$.

Existen varias disposiciones relevantes en relación a las entidades de gestión colectiva que otorgan este tipo de licencias y teniendo todas por objetivo evitar que exista un abuso de este recurso que finalmente perjudique a los titulares de derechos. En primer lugar, no cualquier sociedad está autorizada para otorgar estas licencias sino que solo aquellas cuya membresía es representativa del sector que administra dicha entidad. Por ejemplo, si la sociedad gestiona los derechos de autor o derechos conexos que derivan del uso de obras musicales, esta entidad deberá tener una cantidad de miembros tales que agrupe a un importante porcentaje de los titulares de dichas obras o prestaciones en el país donde está constituida. En segundo lugar, se exige que la sociedad que esté autorizada para otorgar estas licencias cumpla con un código de conducta específico. En tercer lugar, las sociedades de gestión colectivas no están obligadas a otorgar este tipo de licencia sino que lo podrán hacer única y exclusivamente cuando lo consideren adecuado (al igual que el organis-

79 Deazley y Stobo (2013) p. 36.

80 Enterprise and Regulatory Reform Act 2013 policy paper (2013) p. 34. 
mo administrativo regulado en Canadá, entidad que no está obligado a otorgar licencias específicas) ${ }^{81}$.

La LCA no es una creación original del Reino Unido sino que es un mecanismo jurídico que se utiliza desde hace varios años, principalmente en los países nórdicos. Las ventajas de esta regulación están siendo evaluadas por otros países y autores, quiénes destacan el hecho de que este tipo de licencias es especialmente adecuado para ser utilizado en países donde los titulares de derechos están bien informados y organizados. Asimismo, son útiles en aquellos países en que la mayoría del material protegido por la propiedad intelectual que se utiliza proviene del extranjero, lo que dificulta la obtención de autorizaciones individuales ${ }^{82}$.

Tanto los organismos estatales como la doctrina señalan que son varias las ventajas que este tipo de licencias generan ${ }^{83}$. Por un lado, es un mecanismo que asegura un pago de tarifa por el uso de las obras que forman parte de la autorización, incluyendo aquellas conocidas como obras huérfanas. De esta forma se permite que los titulares de derechos se vean beneficiados económicamente por la explotación de su obra o prestación. Es importante destacar que el beneficio monetario que genera la tarifa debe ser percibido tanto por los titulares de derechos que son miembros de la sociedad de gestión colectiva como por los que no lo son. En este sentido, los miembros de la entidad de gestión no tienen el monopolio sobre dicho beneficio. La licencia también facilita la tramitación de la autorización ya que en este caso se exige la realización de un solo trámite que agrupa a varias obras y prestaciones, evitando de esta forma la tramitación y negociación individual de una autorización por cada obra que se pretende usar. Es justamente esta simplificación del sistema de autorización la que lleva a varios autores a sostener que las LCAs son el mecanismo más adecuado para administrar o gestionar la propiedad intelectual en el mundo digital. La facilidad de la tramitación a su vez está dada por otros factores. En el caso que la licencia incorpore obras huérfanas, no será necesario que la persona que presenta la solicitud de uso realice una búsqueda exhaustiva previa para acreditar que el titular de derechos no la podido ser localizado o identificado. En este caso, la obra huérfana se entenderá incorporada en la licencia al igual que todas las obras que tienen características similares. En el caso que el titular apareciera y notara la utilización de su material a través de esta licencia, él podrá hacer uso del sistema opt-out y excluir su obra o prestación de la licencia, pero este solo podrá ser un acto a posteriori. A su vez, si se llegase a detectar el uso de una obra huérfana dentro del repertorio, normalmente se exige que la sociedad de gestión colectiva realice la búsqueda exhaustiva del titular de derechos con la finalidad de poder pagarle los beneficios económicos que ha generado su obra, o si la persona no puede ser identificada o localizada, se sepa que ella tendrá derecho a obtener el beneficio económico si llegase a ser identificada. Este resguardo busca evitar que se realice un abuso sobre la explotación de obras huérfanas, junto con transferir el costo de búsqueda del titular de derechos desde el usuario a la entidad de gestión colectiva, asumiendo que esta tiene mayores recursos para concluir con éxito dicha búsqueda. En cuanto a la licencia, se indica que esta logra balancear los intereses in-

\footnotetext{
${ }^{81}$ Enterprise and Regulatory Reform Act 2013 policy paper (2013) p. 35.

82 Gervais (2003) p. 16.

83 Enterprise and Regulatory Reform Act 2013 policy paper (2013); GERVAIS (2003) p. 8.
} 
volucrados en la regulación de propiedad intelectual, ya que su contenido es específico, es decir, no se debe autorizar una explotación amplia sino que se deben individualizar de forma particular cuáles son los usos que puede realizar la persona que obtiene la licencia y las condiciones de los mismos, como por ejemplo, el tipo de actividad en que se va a permitir que la obra sea usada. Finalmente, la LCA da seguridad jurídica a los usuarios ya que ellos van a poder confiar en que no van a ser objeto de demandas por infracción a la propiedad intelectual, ya que la licencia abarca todas las obras que reúnen las características individualizadas en la autorización ${ }^{84}$.

\section{LECCIONES PARA UNA POTENCIAL REGULACIÓN CHILENA SOBRE OBRAS HUÉRFANAS}

Luego de haber estudiado tres regulaciones que a través de diversos mecanismos dan una respuesta al problema que generan las obras huérfanas, es necesario analizar las ventajas y limitaciones de las mismas con el propósito de tenerlas como un referente para una potencial regulación chilena.

En cuanto a la regulación de excepciones establecidas en la Directiva del Parlamento Europeo, considero que este es el sistema más limitado de todos y que no tendría sentido incorporarlo (con evidentes adaptaciones para dar cuenta de la realidad nacional) en la regulación chilena. El régimen de excepciones creado por el Parlamento Europeo tiene una aplicación muy restrictiva: (1) solo es aplicable en favor de ciertas instituciones; (2) se permiten usos limitados de la obra o prestaciones en cuestión; y (3) no se puede utilizar con todo tipo de obras o prestaciones protegidas por la propiedad intelectual. Estas limitaciones se pueden explicar debido a que el uso de la excepción no requiere de ningún tipo de autorización previa de parte del titular de derechos o de una organización habilitada por ley. Es por lo mismo que las excepciones normalmente son limitadas y se circunscriben dentro de un ámbito de explotación no comercial de la obra o prestación.

Este criterio es también aplicable a las excepciones de fair use contenidas en los regímenes que siguen la tradición del copyright, los que muchas veces a pesar de tener una excepción aparentemente amplia, su aplicación finalmente puede llegar a ser incluso más restrictiva, limitando las posibilidades de uso de las obras sin previa autorización ${ }^{85}$.

Por un lado, toda solución al problema del uso y explotación de las obras huérfanas debería permitir la explotación comercial de las mismas, ya que justamente lo que se intenta es evitar que estas obras sean excluidas del mercado debido a la falta de identificación o localización del titular de derechos, limitando de tal forma su acceso de parte de usuarios. Por otro, reconociendo la importancia de ponderar todos los intereses involucrados en la disyuntiva, es importante que en la medida que el titular de derechos logre ser identificado o localizado, este pueda recobrar el control sobre su trabajo y acceder a un beneficio económico siempre que su obra o prestación haya sido objeto de dicha explotación comercial

${ }^{84}$ Enterprise and Regulatory Reform Act 2013 policy paper (2013) p. 35; Deazley y Stobo (2013) passim; Gervais (2003) p. 8; Olsson (2005) passim.

${ }^{85}$ Ver Davies (1995) pp. 964-989. 
(para los usos no comerciales se puede fijar una tarifa simbólica). Esto debido a que para todos los efectos legales él sigue siendo titular de los derechos que genera la propiedad intelectual, e incluso lo fue durante el tiempo en que se consideró que la obra sobre la que tiene control era huérfana. Es en este sentido que el régimen de licencias especiales se torna interesante. El tribunal u organismo administrativo facultado para otorgar dichas licencias tiene amplias facultades para evaluar el uso que se haga de las obras huérfanas y fijar una tarifa por su explotación.

Es importante destacar el aporte que implica que la entidad administrativa pueda autorizar varios tipos de uso sobre la obra huérfana. Esto significa que el tercero puede ser autorizado no solamente a reproducir la obra huérfana dentro de un formato o actividad determinada por el organismo administrativo, sino que eventualmente también se le puede permitir la realización de otro tipo de explotaciones, tales como la modificación de la misma mediante su utilización para la creación de una obra derivada. Normalmente, en los países que no tienen un régimen legal que regule las obras huérfanas pueden haber terceros que estén dispuestos a asumir el riesgo y utilizar estas obras esperando que nadie note la infracción y le exijan responsabilidad civil y penal. Si el tercero llegase a ser identificado como infractor, junto con asumir la responsabilidad civil y penal, deberá eliminar de su trabajo las obras que son objeto de la infracción. Algunos autores explican que el costo que asume el tercero cuando la infracción se debe a la reproducción masiva de obras es menor, ya que la disminución de dicho catálogo no implica su destrucción o desaparición ${ }^{86}$. A diferencia de ese caso, es más difícil que los terceros estén dispuestos a asumir el riesgo de utilizar de forma ilegal una obra huérfana mediante su modificación para la creación de una obra derivada. Esto se debe a que en el caso que la infracción sea detectada, el infractor no solo va a tener que asumir la responsabilidad civil y penal por vulnerar la ley sobre propiedad intelectual, sino que para poner fin a la vulneración va a tener que destruir la obra derivada, ya que su sola presencia representa una continuación de la infracción que debe cesar. En este caso, el costo de destrucción que genera la incertidumbre del uso de una obra huérfana es infinitamente superior y por eso las personas generalmente no están dispuestas a asumirlo ${ }^{87}$. En este sentido, el sistema de licencias específicas pone fin a esta incertidumbre y permite que las obras huérfanas sean objeto de transformación asegurando la subsistencia de la obra derivada en el caso que el titular de derechos sea identificado o localizado. Dicha certeza y flexibilidad es la que permite concluir que la regulación chilena sería beneficiada por la incorporación de un régimen de licencias especiales para regular el uso de las obras huérfanas, tal como el que existe en Canadá.

Ahora bien, a pesar de que el régimen de licencias especiales constituye un gran avance para solucionar el problema que presenta el uso de obras huérfanas, este mecanismo no da una respuesta adecuada para todos los ámbitos que requieren la regulación de estas obras. Como ya fuese adelantado cuando se estudió el sistema mixto establecido en el Reino Unido, las LCAs cumplen una función específica para la utilización de las obras huérfanas que no puede ser reemplazada por las licencias específicas. Las LCAs dan una respuesta adecuada

\footnotetext{
86 VAN Gompel (2012) passim.

87 Van Gompel (2012) passim.
} 
para asegurar un sistema de licencias en Internet, en particular sobre el uso masivo que se puede hacer de un sinnúmero de obras a la vez. Cualquier proyecto de digitalización masiva va a encontrar obstáculos en la obtención de una licencia específica de uso de obras huérfanas ya que dicha licencia exige que la persona que desarrolle dicho proyecto identifique cuales son las obras huérfanas que forman parte del catálogo que quiere crear y demuestre que ha hecho esfuerzos razonable para poder identificar o localizar al titular de derechos pero que estos han sido infructuosos. Esta búsqueda genera altos costos económicos y de tiempo, que según algunos autores deberían ser evitados ya que entre más ineficiente sea el sistema de obtención de licencias para que terceros usen obras en Internet de forma masiva (incluyendo obras huérfanas), más irrelevante se va a tornar la propiedad intelectual ${ }^{88}$. Esto se debe a que las personas no van a considerar como una posibilidad real la obtención de la licencia y simplemente van a preferir usar la obra asumiendo el riesgo de que les hagan responsables por dicho acto ${ }^{89}$. En este sentido, tal como lo sugiere Stef van Gompel, todo país que pretende resolver el problema de explotación de las obras huérfanas debería tener un sistema mixto que regule por un lado las LCAs para los casos de proyectos de digitalización masiva, y a su vez un régimen de licencias específicas cuyo uso es adecuado cuando el tercero pretende usar una obra huérfana específica para desarrollar un proyecto específico, incluyendo la posibilidad de -incluso- solicitar una autorización para transformar o modificar la obra $^{90}$. Este último caso resolvería el problema que existe en la actualidad en Chile sobre la imposibilidad de usar la obra de Salvador Reyes fuera de las excepciones legales.

Hay que destacar que no basta con reconocer los beneficios que genera el otorgamiento de una licencia tipo LCA para concluir que esta es aplicable a cualquier tipo de país. Para que las ventajas de este tipo de licencias sean efectivas, varios autores resaltan el hecho de que se debe contar con sociedad de gestión colectiva suficientemente desarrolladas, lo que exige tener una estructura administrativa compleja, convenios con organizaciones que gestionan derechos de autores extranjeros y una cantidad de miembros suficientes que permita asegurar que la sociedad representa a un número significativo de autores o titulares de derecho ${ }^{91}$. Es decir, este sistema de licencias nos obliga a analizar la realidad chilena para verificar si el sistema de gestión colectiva nacional puede responder a las exigencias propias de este mecanismo legal. Asimismo, la extensión de la evaluación de las sociedades de gestión colectiva dependerá del ámbito de aplicación de la posible regulación legal. En la medida que se pretenda hacer aplicable la LCA a todo tipo de obra o prestación amparada por la propiedad intelectual, se deberá evaluar en detalle el funcionamiento de cada una de las entidades de gestión que lidian con dichas áreas de desarrollo, como por ejemplo, la gestión de obras musicales, interpretaciones, obras plásticas, obras visuales, etc. En caso que solo se pretenda hacer aplicable la LCA a algún tipo de prestación u obra en particular, el ámbito de evaluación se reduciría solo a dichas esferas por lo que los requerimientos serían exigibles a menos entidades.

\footnotetext{
88 Gervais (2003) passim.

89 Deazley y Stobo (2013) p. 36; Gervais (2003) p. 9.

90 Van Gompel (2012) p. 1360.

91 Ver Van Gompel (2012) passim; Gervais (2003) passim.
} 
En relación con la situación actual de las sociedades de gestión colectiva, es posible señalar que en la actualidad existen sociedades de gestión colectiva en Chile suficientemente desarrolladas y que contemplan mecanismos para lidiar con la administración de obras huérfanas. Este es el caso de la Sociedad Chilena del Derecho de Autor (SCD), entidad que gestiona los derechos de obras musicales. Jorge Mahú, director jurídico de dicha organización explica que la existencia de obras huérfanas es menos frecuente en relación con las obras musicales, ya que existe una larga tradición del ejercicio colectivo de derechos, lo que en la práctica ha generado amplias bases de datos de obras y titulares, existiendo constancia incluso de las transferencias de derechos, información sobre titulares derivados, ya sean cesionarios, herederos, o legatarios.

A pesar de que estas bases de datos disminuyen la posibilidad de que existan obras huérfanas, estas igual están presentes. La opción que han tomado las sociedades de autores musicales, a nivel mundial e incluyendo a la SCD, es la implementación de mecanismos de detección y resolución de estos casos. Estos casos son conocidos como "utilizaciones no identificables", correspondiendo a aquellas situaciones en que la información recibida de los usuarios no se puede asociar a ninguna de las obras documentadas en la sociedad de gestión colectiva del país en el que ha tenido lugar la utilización y que, por consiguiente, no puede dar lugar a un reparto de derechos. Mahú señala que en aquellos casos, al momento de realizar el reparto se aprovisionan fondos disponibles para estas utilizaciones no identificadas, y luego de que se consultan los propios registros y miembros, se crea y difunde un archivo de "utilizaciones no identificadas". Este archivo es realizado utilizando un formato estandarizado por la Confederación Internacional de Sociedades de Autores y Compositores (CISAC), y se difunde entre todas las sociedades musicales, a fin de que estas colaboren, durante un plazo razonable, en la identificación de las mismas. Una vez recibida la documentación pertinente de las obras, de los propios miembros o de una sociedad extranjera, se registran los datos de la obra y se procede vincularla con las "utilizaciones no identificadas". De esta forma, los derechos correspondientes se incluyen en un próximo reparto ${ }^{92}$.

Finalmente, la regulación que se decida implementar el Chile también tiene que tener la particularidad de respetar el ya explicado "test de los tres pasos", ya que nuestro país es miembro del Convenio de Berna y del Tratado ADPIC.

Finalmente, es importante tener presente que las tres regulaciones estudiadas son aplicables en países que han suscrito tanto el Convenio de Berna como el Tratado ADPIC, por lo que de esta forma se puede deducir que estas tres alternativas satisfacen el ya mencionado "test de los tres pasos". De esta forma, todas las legislaciones respetan los intereses de los autores o titulares de derechos e impiden que la restricción impuesta para asegurar el acceso a las obras huérfanas interfiera en forma desmedida con el ejercicio de las facultades establecidas en la ley. De esta forma, la incorporación de alguna de las tres alternativas nombradas, más allá de las ventajas o limitaciones que puedan generar en cuando a su mecanismo de solución del uso de las obras huérfanas, pondera de forma balanceada los intereses que rodean la propiedad intelectual, y en especial no perjudican la posición de los autores o titulares de derechos.

92 Entrevista a Jorge Mahú, director jurídico de la SCD, fecha 1 de septiembre 2014. 


\section{BIBLIOGRAFÍA CITADA}

Busaniche, Beatriz, "Argentina Copyleft. La crisis del modelo de derecho de autor y las prácticas para democratizar la cultura”, Fundación Vía Libre.

Colangelo, Giuseppe, Lincesso, Irene (2012): "Law versus Technology: Looking for a Solution to theOrphan Work's Problem", International Journal of Law and Information Technology, Vol. 20, No 3: pp. 178-202.

Collections Trust (2009): "In from the Cold. An Assessment of the Scope of "Orphan Works" and its Impact on the Delivery of Services to the Public" Disponible en: http:// sca.jiscinvolve.org/wp/files/2009/06/sca_colltrust_orphan_works_v1-final.pdf

Declaración de AAP publishers. Disponible en: http://publishers.org/press/85/

Davies, Gillian (1995): “The Convergence of Copyright and Authors' Rights - Reality or Chimera?", International Review of Intellectual Property and Competition Law, Vol. 26 (6): pp. 964-989.

De Beer, Jeremy; Bouchard, Mario (2009): “Canada’s “Orphan Works” Regime: Unlocatable Copyright Owners and the Copyright Board”. Disponible en: http://www.cb-cda. gc.ca/about-apropos/2010-11-19-newstudy.pdf

Deazley Ronan; Sтово Victoria (2013): “Archives and Copyright: Risk and Reform” Disponible en: http://www.create.ac.uk/wp-content/uploads/2013/04/CREATe-WorkingPaper-No-3-v1-1.pdf

Gervais, Daniel (2003): "Application of an Extended Collective Licensing Regime in Canada: Principles and Issues Related to Implementation" Disponible en: http://works. bepress.com/cgi/viewcontent.cgi? article $=1029 \&$ context=daniel_gervais

Google Books. Disponible en: http://www.google.com/googlebooks/about/history.html

Government Policy Statement: Consultation on Modernising Copyright (2011): Disponible en http://www.ipo.gov.uk/response-2011-copyright.pdf

Guadamuz, Andrés (2009): "La identificación y el acceso al patrimonio cultural en el entorno digital” Disponible en: http://www.wipo.int/edocs/mdocs/copyright/es/wipo_cr_ mad_09/wipo_cr_mad_09_topic06_guadamuz.pdf

Macmillan, Fiona (2007): "Altering the contours of the public domain" en MacQueEN y Waelde, Charlotte (eds.), Intellectual Property. The Many Faces of Public Domain, (Edward Elgar Publishing Cheltenham Limited) pp. 98-117.

Hausman, Jerry A. y SidaK, Gregory (2009): "Google and the Proper Antitrust Scrunity of Orphan Books", Journal of Competition Law \& Economics, Vol. 5(3): pp. 411-438.

Olsson, Henry (2005): "The Extended Collective Licence as Applied in the Nordic Countries” Disponible en http://www.kopinor.no/en/copyright/extended-collective-license/ documents/the-extended-collective-license-as-applied-in-the-nordic-countries

Pallante, María (2012): "Orphan Works and Mass Digitalization”, Berkeley Technology Law Journal, Vol 27: pp. 1251-1258.

Picker, Randal (2012): "Private Digital Libraries and Orphan Works", Berkeley Technology Law Journal, Vol 27: pp. 1259-1284.

Ringnalda, Allard (2013): “Orphan Works, MassRights Clearance, and Online Libraries: The Flaws of the Draft Orphan Works Directive and Extended Collective Licensing as 
a Solution” Disponible en: http://www.academia.edu/606260/Orphan_Works_Mass_ Rights_Clearance_and_Online_Libraries_The_Flaws_of_the_Draft_Orphan_Works_ Directive_and_Extended_Collective_Licensing_as_a_Solution

Ruiz Gallardo, Claudio (2008): "Hacia una Dogmática para el Acceso a Chile”, en Cerda Silva, Alberto (ed.), Acceso a la Cultura y Derechos de Autor. Excepciones y Limitaciones al Derechos de Autor (Santiago, LOM Ediciones Ltda) pp. 31-53.

SAG, Mathew (2012): "Orphan Work Digitalization", Berkeley Technology Law Journal, Vol 27 pp. $1503-1550$.

Samuelson, Pamela (2011): "The Google Book Settlement as Copyright Reform” Disponible en: http://papers.ssrn.com/sol3/papers.cfm?abstract_id=168358

Urban, Jennifer M (2012): "How Fair Use can Help Solve the Orphan Works Problem", Berkeley Technology Law Journal, Vol. 27: pp. 1379-1429.

Van Gompel, Stef (2012): "The Orphan Works Chimera and How to Defeat it: A View from Across the Atlantic”, Berkeley Technology Law Journal, Vol. 27: pp. 1347-1378.

\section{NORMAS CITADAS}

Ley No 17.336 del 2 de octubre de 1970, sobre propiedad intelectual.

Copyright Act, R.S.C 1985, c. C-42, Canadá.

Directiva 2001/29/CE, de 22 de mayo de 2001, del Parlamento Europeo y del Consejo, relativa a la armonización de determinados aspectos de los derechos de autor y derechos afines a los derechos de autor en la sociedad de la información.

Directiva 2012/28/EU, del 25 de octubre de 2012, del Parlamento Europeo y del Consejo sobre ciertos usos autorizados de las obras huérfanas.

Enterprise and Regulatory Reform Act, 2013, Reino Unido. 